\title{
A figura de Voltaire - Hugh Blair e a arte de escrever história
}

Luís F. S. N ascimento

luisfsnascimento@yahoo.com.br

Universidade Federal de São Carlos, São Carlos, São Paulo, Brasil

resumo 0 presente texto procura entender as razões que levaram o filósofo e crítico escocês Hugh Blair a tomar Voltaire como um modelo para o historiador moderno. Iniciase 0 estudo com uma breve exposição de alguns elementos da concepção de história no pensamento voltairiano e então se passa à consideração que 0 autor britânico faz deles.

palavras-chave Blair; Voltaire; História; Antigos; Modernos; Crítica; Modelo.

Há leis para escrever a história como há para todas as artes de espírito, mas, como nestas, naquela há mais preceitos do que grandes artistas. Voltaire ${ }^{1}$

"Tantos raciocinadores tendo escrito o romance da alma, veio enfim um sábio que modestamente escreveu sua história. Locke desenvolveu a razão humana para o homem, como um excelente anatomista explica as molas do corpo humano. (...) Em vez de definir dum só golpe aquilo que não conhecemos, examina por graus aquilo que queremos conhecer" (VO LTAIR E, 1973a, p.27). Esse trecho extraído da décima terceira das C artas inglesas, publicadas por Voltaire em 17342, apresenta-nos um elemento importante para a compreensão do que o pensador francês entende por história. Locke é meticuloso, preciso, modesto, fala apenas daquilo que pode conhecer, atém-se aos limites do mundo que sua visão e seu entendimento Ihe permitem compreender. ParaVoltaire, o autor do

R ecebido em 16 de junho de 2011. A ceito em 25 de julho de 2011.

doispontos, Curitiba, São Carlos, vol. 8, n. 1, p.63-86, abril, 2011 


\section{4}

Ensaio sobre o entendimento humano é mais um representante de uma postura filosófica que tem em Francis Bacon o seu precursor. Bacon é "o pai da filosofia experimental" (VO LTAIRE, 1973a, p.25), aquele que estabelece as bases para um modo de pensar que procura fundamentos concretos ou dados sólidos que comprovem e atestem o que se diz ou defende. Sua obra N ovum Scientiarum 0 rganum, diz-nos Voltaire, é 0 "andaime para a construção da nova filosofia" (VO LTAIR E, 1973a, p.25), dispositivo que é abandonado assim que o prédio foi concluído. Esse edifício ao qual Bacon oferece as bases e as possibilidades de construção apenas é concluído quando entra em cena outro ilustre personagem da filosofia britânica: N ewton. ParaVoltaire, esse é o grande pensador que faz com que a filosofia corresponda aos anseios e pretensões de uma época. Visto como a figura máxima de um processo de desenvolvimento, $\mathrm{N}$ ew ton apresenta aos homens um mundo novo e moderno:

$\mathrm{N}$ a geometria, o infinito foi submetido ao cálculo. A circulação do sangue nos animais e a da seiva nos vegetais transformaram a natureza para nós. A máquina pneumática deu aos corpos uma nova maneira de existir. E enfim, depois de tantas novidades, o que $\mathrm{N}$ ewton descobriu sobre a luz é digno de tudo o que a humanidade poderia esperar de mais ousado (VO LTAIR E, 1973a, p.35).

Por oposição a essa "filosofia experimental" que começa a ganhar terreno na M odernidade encontramos o queVoltaire, no trecho que se referia a Locke como sendo um historiador da alma humana, denomina romance3. Trata-se de um termo que o pensador francês emprega de modo pejorativo, que descreve um uso desregrado, pouco preciso e fantasioso das faculdades de conhecimento. É nesse sentido que D escartes, malgrado seu grande gênio e espírito científico, é definido como sendo um romancista, pois se deixa levar por uma imaginação fértil e, assim, afasta-se do experimentalismo que anima os pensadores britânicos desde Bacon:

D escartes nasceu com uma imaginação viva e forte, tornando-se um homem singular tanto na vida privada quanto no modo de raciocinar. A imaginação não pôde ocultar-se nem mesmo em suas obras filosóficas, cheias de comparações engenhosas e brilhantes. A natureza o fez quase poeta, e, de fato, compôs para a rainha da Suécia uma serenata em versos que, para a honra de suas memórias, não se mandou 
imprimir. (...) A geometria era um guia que de algum modo ele próprio havia formado, e que poderia tê-lo conduzido com segurança na física; no entanto, abandonou o guia em favor do espírito de sistema. A partir de então, sua filosofia foi apenas um romance engenhoso e, quando muito, verossímil para os ignorantes. Enganou-se a respeito da natureza da alma, das provas da existência de $D$ eus, da matéria, das leis do movimento, da natureza da luz (VO LTAIR E, 1973a, pp. 29-31, grifo nosso).

$\mathrm{N}$ ascido para "descobrir os erros da A ntiguidade, a fim de substituí- los pelos seus próprios", D escartes é "arrastado pelo espírito de sistema que cega os maiores homens" (VO LTAIR E, 1973a, p.27, itálicos nossos). Produtor de quimeras e de fantasias engenhosas, esse "espírito" 4 se opõe àquilo que faz de Locke um historiador da alma5. Se não deixa de afirmar que seu conterrâneo é levado a essa postura filosófica por sua natureza imaginativa de "quase poeta",Voltaire também nos lembra que muito do que se vê ou se lê em D escartes é fruto do clima político-religioso no qual o autor do $D$ iscurso do método viveu e das adversidades que essa atmosfera lhe proporcionou. Ao contrário de Locke e de N ewton, D escartes não teve a sorte de nascer em um país mais tolerante e aberto ao livre debate de ideias:

D eixou [D escartes] a França porque procurava a verdade, então perseguida pela miserável filosofia da Escola. M as não encontrou mais razão nas universidades da $\mathrm{H}$ olanda, para onde se retirava, pois, na época, em que na França as únicas proposições verdadeiras de seu sistema eram condenadas, também foi perseguido pelos pretensos filósofos da $\mathrm{H}$ olanda, que não o compreendiam melhor e que, vendo sua glória mais de perto, odiavam ainda mais sua pessoa. Foi obrigado a sair de U trecht: aguentou a acusação de ateísmo, último recurso dos caluniadores. (...) Por fim, em virtude de um mau regime, morreu prematuramente em Estocolmo entre sábios, seus inimigos, e nas mãos de um médico que o odiava (VO LTAIR E, 1973a, p.30).

R echaçado, invejado, perseguido, caluniado, a vida de Descartes foi 0 oposto da tranquilidade que caracterizou a de $\mathrm{N}$ ew ton - homem morto aos oitenta e cinco anos, sendo sempre honrado e festejado por seus 
conterrâneos. Pôr esses dois autores lado a lado, como faz a décima quarta das $C$ artas inglesas, é também destacar as condições que possibilitaram o bom curso e o aprimoramento das ideias do britânico. A "feliz mistura no governo da Inglaterra, esse acordo entre a $C$ âmara dos $C$ omuns, a dos Lordes e o rei" (V O LTAIR E, 1973a, p.20), permite aos seus cidadãos uma condição bastante diversa daquela dos súditos da coroa francesa, a ponto de um membro da Câmara dos C omuns poder iniciar seu discurso "com as seguintes palavras: 'A majestade do povo inglês seria ferida...etc'" (VOLTAIRE, 1973a, p.18). A majestade não é atributo exclusivo do monarca. EmboraVoltaire saiba manter um posicionamento crítico frente à Inglaterra do seu tempo, postura que também Ihe permite reconhecer qualidades em sua terra natal, ele não esconde o seu entusiasmo diante da forma de governo que reina entre os ingleses e da "sábia liberdade" (VO LTAIR E, 1973a, p.19) que ela promoveu. Foi esse o ambiente que possibilitou o pleno desenvolvimento de uma atitude filosófica moderna, diferente e mesmo superior à antiga.

0 autor das $C$ artas inglesas dirige uma crítica aos pensadores da A ntiguidade que não difere muito daquele diagnóstico que o vimos fazer da filosofia cartesiana. Para ele, os antigos são marcados por um espírito fantasioso e imaginativo que torna suas obras similares às fábulas e aos romances ${ }^{6}$. Pior: há por toda a A ntiguidade uma forte presença da superstição e de uma religiosidade que a desvia da verdade. 0 próprio Sócrates, lembra-nos a C arta XIII, está intimamente ligado à ideia de um gênio ou demônio que o orienta em seus argumentos. A ciência e a história antigas se assemelham a contos de fadas nos quais a má composição dos personagens acompanha o obscurantismo, e não era raro que então se vinculasse à narração ou descrição de um fenômeno natural alguma explicação supersticiosa, como acreditar que " os cometas eram sempre os batedores de alguma grande desgraça que deveria cair sobre a Terra" (VO LTAIR E, 1973a, p.34). É esse tipo de postura que começa a ser questionada por um novo modo de pensar:

A costumado [N ewton] a desenredar o caos, quis trazer pelo menos alguma luz ao das fábulas antigas, confundidas com a história, fixando uma cronologia incerta. É verdade que não há família, cidade nação que não procure recuar sua origem, e além disso, os primeiros historiadores foram sempre os mais negligentes na marcação das datas. 
O s livros eram mil vezes mais raros do que hoje, consequentemente, menos expostos à crítica - enganava-se o mundo mais impunemente. $E$ visto que se até os fatos foram supostos, muito provavelmente as datas também o foram. De um modo geral, segundo N ewton, o mundo seria quinhentos anos mais novo do que dizem os cronologistas. Para fazer tal afirmação $\mathrm{N}$ ewton recorre à observação do curso ordinário da natureza e a observações astronômicas (VO LTAIR E, 1974, pp.37-38).

É imbuído desse mesmo espírito queVoltaire escreve suas $\mathrm{N}$ ovas considerações sobre a história, texto no qual ironiza e ataca "toda essa massa de tolices célebres com as quais os antigos historiadores se regozijam" (VO LTAIR E, 1996, p.87). R imos, escreve o francês, quando lemos nesses autores que " dois batal hões de serpentes se defrontaram perto deTournai em 1059" ou então quando falam de uma armada constituída de ratos e que teria derrotado e comido "o famoso 0 ton, arcebispo de M aience" (VO LTAIR E, 1996, p.86). C omo um N ew ton,Voltaire clama por clareza e meticulosidade no trato com os fatos históricos: "Q uero falar aqui da história moderna, na qual não se encontram mais bonecas que beijam os cortesãos, nem bispos comidos por ratos" (VO LTAIR E, 1996, p.87).

É esse olhar moderno que agora torna viável a noção de uma história que se opõe ao que até então era feito. Como dizia Voltaire em um trecho citado acima, se antes era possível enganar impunemente o público com as narrativas mais extraordinárias, agora com a difusão dos livros e com a crescente formação de um público leitor e crítico, fica cada vez mais difícil esse tipo de embuste. 0 mundo moderno parece então oferecer as condições para o desenvolvimento de uma história tão coerente quanto verdadeira. Para levar tal projeto a cabo, é necessário que se ouse colocar em dúvida a autoridade dos antigos e detectar o que neles é fal so e fabuloso: é preciso, por exemplo, abandonar o respeito cego e irrefletido por tudo o que provém da G récia, "berço das artes e dos erros, onde a grandeza e a tolice do espírito humano tanto se desenvolveram" (VO LTAIR E, 1973a, p.26). A exemplo do que deve ocorrer em todas as áreas do conhecimento moderno, a história também tem de ser experimental, se por esse termo compreendermos aquele modo de pensar e proceder que se inicia com Bacon. 0 historiador precisa ater-se às circunstâncias, as datas e aos fatos, sem o que seu relato será tão artifi- 
cioso quanto um romance. Tendo em vista essa exigência ou preocupação em relação à análise, à observação e à precisão que devem caracterizar a história, faz então sentido atribuir a Locke o epíteto de historiador da alma ou afirmar que $\mathrm{N}$ ewton é uma espécie de narrador dos fenômenos naturais.

$M$ as para que se atinja o queVoltaire denomina como sendo propriamente história, é necessário que se considere outro elemento, algo imprescindível àquele cujo âmbito de atividade não diz respeito ao relato dos movimentos ou evoluções da alma ou do mundo natural, mas se dedica à narração da vida social e política dos homens. Para além da postura experimental que confere rigor ao seu trabalho, o historiador também tem de saber agradar e entreter o seu leitor7. E é nesse momento que sua ocupação se aproxima da do bom poeta que, diferentemente do romancista, é capaz de construir uma obra tão coerente quanto bela. Ao comentar os escritos deVoltaire que versam sobre temas históricos, $R$ ené Pomeau nos lembra que quando fala de história e, sobretudo, na ocasião em que escreve ou faz história,Voltaire emprega com frequência o termo tableau, quadro:

U m quadro: é o termo queVoltaire emprega habilmente para caracterizar o seu Século de L uís XIV. U m quadro no lugar de uma história. (...) 0 s eventos são situados como que na profundidade visual: no primeiro plano, as batal has; no segundo, o esplendor deVersalhes (PO M EAU, 1957a, pp.10-11).

Em uma carta a H énault de 8 de janeiro de 1752, é o próprio Voltaire quem afirma o mesmo acerca de seu Séaulo de L uís X IV , obra impressa no final do ano anterior: " Pretendi fazer um quadro dos eventos que merecem ser pintados e manter os olhos do leitor presos aos principais personagens" (apud PO MEAU, 1957a, p.10). Se o historiador deve ater-se aos fatos e à observação atenta dos fenômenos que descreve, tal como faz um Locke em relação ao entendimento humano, ele também tem de saber reconhecê-los como sendo elementos interligados, tal como os personagens que compõem uma pintura. É preciso mesmo reconhecer aquele que em meio à multiplicidade que forma a cena assume o papel de protagonista e, assim, confere unidade à tela que o historiador busca produzir: "o drama da história não se concebe sem protagonistas" , acres- 
centa Pomeau (1957a, p.11). É exatamente o que fazVoltaire a partir de Luís XIV. A figura desse rei é o ponto ou tema pelo qual ele poderá estruturar e compor o quadro que deseja apresentar ao seu público, como atesta uma carta que o filósofo envia a M ilord H ervey:

$\mathrm{N}$ ão considero somente Luís XIV porque ele fez bem aos franceses, mas porque fez bem aos homens; é como homem e não como súdito que escrevo. (...) Q uero pintar o último século e não apenas um príncipe, em uma palavra, é antes de um grande século do que de um grande rei que escrevo a história. (VO LTAIR E, 1957b, p.611).

N ão se trata então da história de Luís X IV, mas da história da qual esse rei é figura: sua imagem é a dos avanços de um tempo ou de uma cena que começa a ganhar corpo antes mesmo que sua presença seja explicitada e termina quando o rei já está morto. "Fixei essa época em alguns anos antes de Luís XIV e alguns anos depois: é, com efeito, nesse espaço de tempo que o espírito humano fez os maiores progressos" (VO LTAIR E, 1957c, p.1022). Luís X IV não é essa época, ele é o seu protagonista: aquele que a melhor representa, o rosto que Ihe dá identidade. Interessa a Voltaire narrar os extraordinários avanços do espírito humano ocorridos nesse século e não fazer uma biografia. Como ele mesmo explica a M ilord H ervey na carta acima citada, seu desejo não é o de se limitar à França seiscentista, mas pintar uma época a partir dessa França. A influência desse país e desse reinado em especial sobre o aprimoramento das artes e das ciências vai muito além do território francês e chega, por exemplo, à Inglaterra: sem as experiências de "M onsieur Picard", diz-nos Voltaire, "N ewton jamais haveria feito suas descobertas sobre a atração" (VOLTAIRE, 1957b, p.610). O mesmo intercurso entre França e Inglaterra, tão presente nas $C$ artas inglesas, tem agora de ser apresentado sob um outro aspecto ou ângulo: para que o quadro que se pretende fazer seja bem pintado tudo tem de girar em torno do R ei Sol, ponto que conecta todos os elementos, fatos ou lugares que se deseja exibir na tela. Como não poderia deixar de ser, esse ponto indispensável à feitura da pintura histórica é bem localizado, particular ou pontual. Diz respeito a um tempo e a condições específicas (trata-se de um rei nascido ou morto em uma determinada data, de uma certa nacionalidade, com um nome etc.), mas nas mãos do bom historiador também pode ganhar 
feições universais e ultrapassar o que nele é meramente circunstancial, na medida em que expõe algo que é próprio da humanidade. Esse é um dos propósitos do seu Século de L uís XIV , um livro que sem deixar de ser a narração de fatos específicos e precisos, é também a história do espírito humano e de suas luzes, como mostra o final do Capítulo XXXIV dessa mesma obra: "Basta aqui fazer com que se veja que no século passado os homens adquiriram mais luzes de um extremo ao outro da Europa do que em todas as épocas anteriores" (VO LTAIR E, 1957c, p. 1028).

A Europa toda tem de ser vista nesse quadro que, no entanto, não deixa de ser o do reinado de Luís XIV. M ais do que isso: essa pintura tem de pressupor a ideia de humanidade como um todo, sem a qual não se poderia apresentar esse século como um período privilegiado para os homens?. Como havíamos dito acima, algo maior que a mera descrição de fatos datados e circunstanciais está presente no trabalho do historiador. D esse ponto de vista, aquele que se ocupa com a história assume uma tarefa que, em certa medida, lembra al guns aspectos da atividade do comediógrafo. $\mathrm{D}$ e acordo com a décima nona das $\mathrm{C}$ artas inglesas, as tragédias produzem personagens universais: “É dipo, E letra pertencem aos espanhóis, aos ingleses e a nós, como aos gregos. M as a boa comédia é a pintura falante dos ridículos de uma nação e se não conheceis a nação a fundo não podereis julgar a pintura" (VO LTAIR E, 1973a, p.43). Diferentemente do poeta trágico, o cômico trabal ha com tipos particulares, próprios de um determinado país, com um sotaque bem preciso. 0 caráter doméstico ou nacional das comédias faz com que sejam ininteligíveis para aquele que desconhece as particularidades das quais é feita, o que torna inócuo 0 trabalho de traduzi-las: "não se ri numa tradução" (VO LTAIR E, 1973a, p.43). 0 u seja: se retirarmos os personagens cômicos do quadro ou do cenário ao qual pertencem, eles perdem o sentido e sua razão de ser: seu vínculo com o solo de origem é indissociável. Ao contrário de Édipo ou Eletra que podem falar todas as línguas, pois são universais, tipos que saem da pena de um Congreve não poderão ter sobre um francês o mesmo efeito que tem sobre um conterrâneo britânico. " $\mathrm{N}$ ão tenho prazer lendo Plauto ou Aristófanes. Por quê? Porque não sou romano nem grego" (VO LTAIR E, 1973a, p.43), acrescenta o autor das C artas. Personagens cômicos estão presos à sua realidade factual e à sua circunstância histórica. $\mathrm{N}$ o entanto, como também lembra Diderot a esse respeito, não podemos 
confundir a boa comédia com a mera farsa ou com a sátira: "A sátira é de um tartufo, e a comédia é do Tartufo. A sátira persegue um vicioso, a comédia persegue um vício" (DIDER OT, 2000, p.54).

Por mais doméstica que seja, mesmo que sempre esteja circunscrita à realidade de um país e de uma época, a boa comédia não pode ser identificada à simples caricatura de alguém ou de um período. Q uando bem composto, o drama cômico apresenta personagens e o Tartufo já não é mais um tartufo em especial. A condição que Voltaire prescreve para 0 entendimento de uma comédia é o conhecimento da nação que lhe deu origem: assim, para que se possa rir com Molière e apreender todo 0 alcance de seu trabalho bastaria um bom conhecimento da fala e dos costumes franceses de sua época. $\mathrm{N}$ o interior dos limites que constituem a França de M olière, o seu Tartufo é inteligível. Embora não seja universal, como afirmaVoltaire, o personagem cômico mantém algo da universalidade de um Édipo na medida em que ele também é uma figura bem composta, que é criada por um poeta e não é uma mera caricatura. $M$ algrado as diferenças que os separam no que diz respeito à poesia dramática10, se é correto pensar que tanto para Diderot quanto para Voltaire a boa comédia não pode ser meramente satírica e caricata, então ao comediógrafo é reservada uma tarefa extremamente complexa: fazer com que os seus personagens, no momento mesmo em que afirmam a sua particularidade e pertencimento a uma nação e época, também possam indicar algo de universal ou próprio do gênero humano. "O único meio para conhecer a comédia inglesa é vir a Londres, permanecer três anos, aprender bem o inglês e a ver a comédia todos os dias" (VO LTAIR E, 1973a, p.43), frisam as C artas inglesas.

Compreender 0 que $\mathrm{N}$ ew ton representou para a Inglaterra e, por extensão, para a humanidade como um todo, não exigiu deVoltaire um esforço ainda maior do que ir a Londres e aprender inglês? N ão teve ele de entender $\mathrm{N}$ ew ton como a manifestação ou expressão mais acabada de um processo de aprimoramento do espírito do qual Bacon e Descartes seriam momentos anteriores? $\mathrm{N}$ ão teve de compreender o mesmo $\mathrm{N}$ ewton como sendo um autor tipicamente britânico e, apesar disso, universal, assim como Luís XIV que, aos olhos do historiador, acaba por se tornar todo o século no qual viveu? Há aqui uma difícil relação que se estabelece no interior de uma concepção de história pensada por analo- 
gia à feitura de um quadro: o elemento ou personagem principal tem de encerrar em si toda a multiplicidade que compõe o universo que ele, como protagonista, figura. Por certo, personagens históricos não são personagens cômicos, tampouco a história poderia ser reduzida a esse gênero específico de drama. M as talvez seja possível pensar que assim como a comédia não poderia ser uma caricatura da vida de seu tempo e país, a história também não pode se limitar a um mero relato de fatos ou se apresentar como uma narrativa de circunstâncias desprovidas de ordem ou arranjo. Faz parte do ofício do bom historiador saber escolher o que deve ser contado e estabelecer os graus de importância em meio aos eventos escolhidos. São essas questões presentes na obra deVoltaire, temas diretamente ligados à noção de composição do texto histórico, que chamarão a atenção do autor que passaremos a analisar a partir de agora.

\section{A pintura dos fatos}

D ois anos após serem publicadas pela primeira vez, as P releç̃es sobre retórica e belles-lettres (L ectures on R ethoric and B elles L ettres) receberam em 1785 uma segunda versão corrigida por seu autor: o escocês Hugh Blair. 0 livro obteve uma considerável reputação na Grã-Bretanha e no decorrer dos séculos X VIII e XIX chegou a ter versões na França, na Alemanha, na Itália, na Rússia e na Espanha (vide FERREIRA-BU CKLEY; HALLORAN, 2005, pp. xix-Xx). Em um prefácio a ele anexado, a origem do volume é narrada pelo próprio Blair. Por vinte e quatro anos 0 autor havia ministrado na U niversidade de Edimburgo uma disciplina chamada R etórica e belas-letras, cujo propósito era o de incentivar os jovens estudantes a "cultivar o seu gosto, a formar o seu estilo ou prepará-los para o discurso público ou para a composição" (BLAIR, 2005, p.1). Q uando percebe que muitas das quarenta e sete preleções que constituíam seus cursos estavam sendo copiadas a partir de notas feitas por alunos e distribuídas a um público interessado, Blair resolve ele mesmo preparar uma edição para esse material. Por essa razão, o livro guarda a forma escolar e se apresenta como um curso:

Elas [as preleções] foram originalmente projetadas (designed) para iniciar os jovens no estudo das Belas-Letras e da Composição. C om a mesma 
intenção são agora publicadas e, portanto, a forma na qual as preleções foram primeiramente compostas foi mantida. 0 autor as entrega ao mundo não como uma obra totalmente original, nem como uma compilação de escritos de outros. Acerca de cada tema nelas contido, ele pensou por si mesmo. Consultou suas próprias ideias e reflexões e a grande maioria do que se encontrará nessas preleções é dele próprio. Ao mesmo tempo, até onde considerou digno de ser adotado, ele se aproveitou das ideias e reflexões de outros (BLAIR , 2005, p.1).

O livro de Blair é antes de tudo uma obra crítica que versa sobre um domínio então bastante difundido e muito importante para uma sociedade que se preocupava em formar seus filhos para os negócios ou afazeres do mundo social, a saber: 0 das belas- letras que, como notam Linda Ferreira-Buckley e S. M ichael H alloran, designa não apenas o estudo dos clássicos, mas também a concepção segundo a qual esse tipo de aplicação é de extrema importância para a vida cívica. A ideia central era a de que o homem bem formado e com uma cultura humanística sólida tende a ser um bom cidadão, promotor dos interesses de sua nação e daqueles da humanidade em geral. A lém de manifestar 0 "reconhecimento" (FER R EIR A-BU CKLEY; H ALLO R AN , 2005, p.xxxv) de Blair em relação a críticos e autores franceses que o influenciaram, como Voltaire, o emprego da expressão belles-lettres no título de sua obra indica uma preocupação do autor frente à época em que vive. Ao explicar em uma carta o motivo pelo qual opta por manter esse termo francês já presente no nome da disciplina que ministrava na universidade, nosso autor afirma que com isso pretendeu dar ao seu livro "um ar mais moderno" (C arta a Eliot, 4 de março de 1763 apud FER R EIR A-BU CKLEY; HALLO R AN , 2005, p.xxxv)11. Embora o mundo antigo e os textos clássicos sejam sempre considerados ao longo das preleções, o universo no qual são escritas e lidas assume um papel de destaque: trata se de um livro moderno que se dirige a um público igualmente moderno. Por isso mesmo aquele que se dedica às belles-lettres não se limita a citar pensadores ou escritores antigos e, como faz Blair, pode considerar em seu exame nomes como os de R ousseau, Diderot, Shakespeare, Addison, Pope, M ilton, H ume etc. Tão importante quanto a análise de autores modernos é a delimitação de certos temas ou assuntos que caracterizam esse âmbito das 


\section{4}

belas- letras: são questões como a do gosto, do gênio, da beleza, do estilo, da linguagem, da eloquência, da poesia e de seus distintos gêneros que estão em causa nas P releções. E é em meio a esses temas que encontramos o da composição de textos históricos, assunto para o qual Blair dedica dois de seus capítulos ou aulas: a preleção XXXV, cujo título é C omparação do mérito dos antigos e dos modernos - arte de escrever histórica (C omparative $\mathrm{M}$ erit of the A ncients and the M oderns - $\mathrm{H}$ istorical W riting) e a XXXVI, denominada A rte de escrever histórica (H istorical writing).

$\mathrm{N}$ o início da primeira delas, Blair nos diz que ali começa uma parte de suas preleções em que se dedicará “à consideração dos mais eminentes gêneros de composição, tanto em prosa quanto em verso" e destacará "os princípios da crítica relativos a eles (gêneros de composição)" (BLAIR, 2005, p.390). 0 método que será empregado, explica-nos o escocês, é o mesmo do das preleções anteriores: Blair irá emitir suas opiniões acerca do assunto levando em conta o que lhe parece "fundado sobre o bom senso e sobre a razão" (BLAIR, 2005, p.390). 0 tema da composição também exige uma comparação sempre presente no livro de Blair entre antigos e modernos. Nesse caso, o paralelo entre Antiguidade e M odernidade se justifica por uma coerência ou adequação frente ao assunto tratado. Segundo o autor, é o próprio tema da composição que exige a consideração do que foi feito pelos antigos e pelos modernos, 0 confronto entre escritores de épocas distintas torna possível "Iançar luz em algumas coisas que posteriormente apresentarei sobre os diferentes gêneros de composição" (BLAIR , 2005, p.390).

A primeira observação acerca da relação entre antigos e modernos é exposta no terceiro parágrafo dessa trigésima quinta preleção e diz respeito ao que Blair chama de "fenômeno notável" (BLAIR, 2005, p.390), a saber: a percepção de que existem certas épocas ou momentos históricos que se destacam pelo grande número de "escritores e artistas" (BLAIR , 2005, p.390), tempos férteis nos quais "a natureza parece ter se exercido com uma força extraordinária", ocasiões em que surgem gênios nos mais variados âmbitos da atividade humana e que se opõem aos períodos "notadamente estéreis" (BLAIR , 2005, p.390). O s motivos que explicam esse fenômeno são óbvios, acrescenta Blair: "circunstâncias de governo e de costumes favoráveis, encorajamento dos grandes homens, emulação entre homens de gênio" (BLAIR , 2005, pp.390-391). Dubos, 
lembra-nos o autor escocês, também chama a atenção para as causas físicas do florescimento das artes e ciências, destacando a influência do ar e do clima atmosférico12. Sem querer prosseguir com o exaustivo exame das causas que ensejam a engenhosidade humana, Blair se atém àquilo que considera como certo e indubitável: existem épocas que se destacam "pela extraordinária produção de gênios" (BLAIR, 2005, p.391). Sua intenção não é a de determinar com precisão os motores desse desenvolvimento, basta-lhe reconhecer nesses eventos algo como um movimento próprio à natureza das civilizações que, de tempos em tempos, ascendem e declinam. Baseado na autoridade daqueles que chama de "learned men", Blair elenca "quatro dessas épocas felizes" (BLAIR , 2005, p.391) nas quais o gênio estava em plena ascensão. A primeira delas é a dos gregos, que se inicia por volta do tempo da Guerra do Peloponeso e vai até Alexandre. É o período em que surgem nomes como os de H eródoto, X enofonte, Sócrates, Platão, A ristóteles, Demóstenes, Ésquilo, Eurípides, Sófocles, Menandro etc. 0 segundo momento é o dos romanos, que se inicia um pouco antes de Júlio C ésar e termina próximo do final do reinado de Augusto. Aqui aparecem autores como Catulo, Lucrécio, Virgílio, H orácio, $O$ vídio, Cícero etc. A terceira das épocas felizes é a que Blair denomina "restauração da erudição (learning)", localizada entre o pontifício de Julio II e 0 de Leão $X$. São desse período $M$ aquiavel, A riosto, $M$ ichelangelo, $R$ afael, Ticiano etc. Por fim, 0 quarto e último momento está situado entre os reinados de Luís X IV e da rainha Ana, período um pouco anterior ao que Blair escreve seu livro. $N$ ele estão Corneille, $R$ acine, M olière, B oileau, R ousseau, Fenelon, $M$ alebranche, Bayle, D ryden, Pope, Addison, Bolingbroke, Locke, Shaftesbury, $\mathrm{N}$ ewton, Clarke etc ${ }^{13}$. Entre os homens que se pode destacar em cada uma dessas quatro épocas, diz-nos Blair, é possível acrescentar o nome de alguns notáveis que viveram um pouco antes ou depois do momento em que artes e ciências estão em seu maior esplendor. É o caso de H omero que antecede o período grego ou de alguns contemporâneos de Blair que dão continuidade ao espírito desenvolvido anteriormente, como ele mostrará na continuidade de sua preleção.

Podemos perceber que na classificação das épocas apresentadas, as duas primeiras são antigas e as duas últimas modernas. $\mathrm{N}$ o que tange à qualidade artística ou ao nível de engenhosidade, afirma Blair, perde tempo 
aquele que busca estabelecer graus de hierarquia a partir dos quais seria possível estabelecer uma superioridade dos antigos em relação aos modernos ou vice-versa. D esse ponto de vista, toda comparação entre M odernidade e Antiguidade corre o risco de ser "vaga e imprecisa" (BLAIR , 2005, p.391). Por essa razão, afirma Blair, a reputação de autores clássicos em nada pode ser abalada por críticas modernas, pois a notoriedade dessas obras "está estabelecida sobre quase todo gosto universal do gênero humano, provado e comprovado ao longo de várias épocas" (BLAIR , 2005, p.392). Isso não quer dizer que não seja possível apontar certos erros ou equívocos na obra de autores tidos como clássicos, " pois onde está a obra humana que é perfeita?" (BLAIR , 2005, p.392). Sempre existirão alguns pequenos problemas, mas eles são detalhes que não podem pôr em risco a integridade da obra de um grande autor. Q uem quer que se oponha a isso, diz-nos Blair, "tem de estar errado, pois a natureza humana está contra ele" (BLAIR , 2005, p.392). D e acordo com nosso autor, ao serem consideradas como clássicas, as obras já foram reconhecidas e receberam o veredicto de um tribunal especial: o gosto do público de várias nações e épocas e, por isso, estão imunes ao menosprezo ou à rechaça de qualquer tempo vindouro. Elas continuarão a ser motivo ou tema de permanente análise ou crítica, mas seu estatuto ou importância não pode mais ser questionado. A parece aqui um argumento que lembra o da duração, sustentado por David Hume em seus E nsaios'14: como afirma o também escocês e amigo de Blair, a obra que persiste, aquela que continua a ser respeitada e lida por séculos merece ser reconhecida como um clássico, pois indica algo que diz respeito à natureza humana: a ideia de um natural taste ou de uma regularidade no modo de julgar ou apreciar as produções do espírito.

M as, como não deixa de salientar B lair, essa noção de duração presente na de clássico se vincula a um domínio preciso que ele chama de matters of taste, questões de gosto. Esse domínio negligencia os "progressos do conhecimento e da ciência" e se relaciona ao âmbito do que nosso autor denomina sentimento: em suas palavras, "sentiments and feelings" (BLAIR , 2005, p.392). De acordo com esse ponto de vista, que é do gosto, é falso o argumento segundo o qual a reputação de um Platão ou de um H orácio se deve às escolas ou às universidades que supervalorizam tudo o que foi escrito em uma língua antiga, "pois o grego e o latim nem sempre 
foram línguas mortas" e as obras desses autores só se tornaram reconhecidas e consideradas como clássicos graças à admiração que despertavam em "seu próprio país e nação" (BLAIR , 2005, pp.392-393). N o que diz respeito ao gosto ou às matters of taste, as obras do espírito humano são tomadas de modo atemporal e aquela que foi considerada bela ontem, também será amanhã. R azão pela qual H omero e Virgílio têm de ser considerados sob a mesma luz que reconhece a maestria e a genialidade de D ryden, Pope ou Addison: todos são igualmente clássicos na mesma medida em que despertam a atenção do gosto.

Algo totalmente diverso ocorre quando se considera o movimento que gera e promove as obras do espírito humano como sendo um conhecimento acumulativo. É desse ponto de vista que se pode pensar em uma classificação hierárquica das produções dos homens de diferentes épocas. Torna-se então possível, exemplifica Blair, dizer que a filosofia natural de $\mathrm{N}$ ew ton é superior à de A ristóteles, pois se reconhece que 0 inglês dispõe de conhecimentos que não eram acessíveis ao grego. Há aqui a noção de progresso ou aperfeiçoamento que não está presente quando nos limitamos unicamente ao âmbito do feeling and sentiment. Ao considerar as evoluções, acrescenta nosso autor, o universo do espírito humano pode ser comparado àquele de uma pessoa que, à medida que vive, adquire novas experiências que aprimoram sua capacidade de julgar e aprender. Assim como alguém mais experiente ou vivido tende a ter mais conhecimentos do que aquele que é ainda muito jovem, seria natural pressupor que os modernos ultrapassassem os antigos:

Daí o fato de que em filosofia natural, em astronomia, em química e outras ciências que dependem de um conhecimento extenso e da observação dos fatos, os filósofos modernos tenham uma inquestionável superioridade sobre os antigos (BLAIR , 2005, p.393).

Trata-se, como dissemos, de um âmbito do espírito humano que é feito e pensado a partir das ideias de progresso e acumulação. A ele Blair confere 0 nome de matters of pure reasoning, por oposição às matters of taste. Dele faz parte o que chamamos de ciência - domínio estranho ao do gosto, que se ocupa das artes e da beleza. N o limite, são dois modos de considerar o mesmo movimento que é o do espírito humano. Certas atividades ou produções dos homens tendem a ser julgadas como sendo 
matters of pure reasoning, outras como matters of taste. $\mathrm{H}$ á, porém, algumas que são de um tipo híbrido: atividades que têm, ao mesmo tempo, algo da duração das matters of taste e do acúmulo ou do progresso das matters of pure reasoning. Para Blair, a história é o grande paradigma dessa mistura: por um lado, ela exige o conhecimento dos "progressos da sociedade", por outro "diz respeito ao gosto e a bela-escritura (fine writing)" (BLAIR , 2005, p. 393). Em uma primeira consideração, o historiador é al guém que não pode deixar de atentar para a verdade factual, tampouco ignorar a evolução ou modificação que ocorre constantemente no universo político e social. N esse sentido, a história se enriquece com a acumulação de conhecimentos e experiências, tal como acontece com a química ou com a astronomia:

0 mundo (de hoje) é mais aberto do que foi nos tempos anteriores (former times), o comércio cresceu enormemente, um maior número de países se civilizou (...), o intercurso se tornou mais simples e, consequentemente, o conhecimento dos fatos mais acessível (BLAIR, 2005, p.393).

Tal como em Voltaire, há para Blair um elemento experimental e científico - de puro reasoning - na história. Por esse motivo, quanto mais eventos históricos nós conhecermos, melhores historiadores seremos. C omo afirma a Trigésima Sexta preleção, nos tempos modernos "uma maior experiência de todos os diferentes modos de governo tornou os homens mais esclarecidos e inteligentes no que diz respeito aos assuntos públicos" (BLAIR, 2005, p.402). A experiência desempenha aqui um papel de extrema importância: o juízo e a capacidade crítica do historiador se desenvolvem quando observa e leva em consideração uma quantidade significativa de fatos, na ocasião em que pode comparar aquilo que vê diante dos seus olhos com o que aconteceu em diferentes épocas de diversos povos. Como Blair não se cansa de afirmar, essa é a razão pela qual os historiadores modernos tendem a ser melhores do que os antigos.

Porém, essa vantagem da M odernidade em relação à Antiguidade acarreta um prejuízo. Em um argumento que mais uma vez lembra o de Voltaire, Blair destaca a forte propensão que os modernos têm pelo que é experimental e factual. M as esse predomínio da observação e da experiência que caracteriza a M odernidade acaba por menosprezar ou pôr de 
lado a constatação de que a história exige de quem a produz um cuidado frente ao modo, à maneira ou ao estilo com que se compõe o texto no qual ela se apresenta. Se ao historiador fosse exigido apenas a observação e a atenção aos fatos, se Ihe bastasse meramente narrar com precisão o que vê ou presencia, então, ao menos em tese, qualquer um poderia reivindicar o título de historiador. $\mathrm{N}$ o entanto, afirma o filósofo escocês, "não é qualquer relato de fatos que recebe o nome de história, por mais verdadeiro que ele possa ser." (BLAIR , 2005, p.397). É nesse momento que uma investigação ou análise acerca do modo como os antigos compunham os seus textos históricos pode ser de grande ajuda para aqueles que desejam fazer o mesmo na M odernidade.

É verdade que o "conhecimento e os materiais dos historiadores antigos eram mais limitados e circunscritos", que eles desconheciam as diversas formas de governo que os modernos conhecem e, por isso, não podiam dominar com clareza "as causas políticas dos assuntos públicos" (BLAIR , 2005, p.402). Seus relatos são muito questionáveis e se apresentam como um misto de "verdade com ficção" (BLAIR , 2005, p.407), no entanto há neles um elemento que não pode ser ignorado quando 0 assunto é a composição histórica: os textos antigos são belos. Eles podem instruir sem deixar de agradar. Podem, portanto, durar e se tornar clássicos e ainda manter algum caráter de fidedignidade, algo de matters of pure reasoning. "Os antigos fizeram uso de um embelezamento da história que os modernos colocaram de lado (laid aside)" (BLAIR , 2005, p.407), escreve 0 autor escocês. Para Blair, este é um problema que a M odernidade tem de enfrentar. É preciso levar em conta esse caráter da história que se evidencia nos trabalhos dos antigos: ela tem de ser bela. Se o historiador tem de corresponder às exigências das matters of pure reasoning para ser preciso, ele também tem de considerar as do gosto para completar sua tarefa e realizar um bom texto histórico. As observações e análises acerca da história antiga e moderna permitem a Blair estabelecer o que julga ser a qualidade principal de um bom historiador. Segundo o autor, é necessário que ele saiba "registrar a verdade para instrução do gênero humano" (BLAIR , 2005, p.402). Sem deixar de instruir, o historiador precisa agradar. Se há algo como uma verdade histórica, ela deve ser buscada no equilíbrio entre esses dois pólos. Para explicar essa difícil posição que a composição histórica deve reivindicar daquele que a pratica, Blair 
lança mão de um exemplo já empregado porVoltaire e recorre à imagem da pintura:

As primeiras virtudes da narração histórica são a clareza, a ordem e a devida conexão. Para atingir isso, o historiador deve dominar completamente o seu tema, sua visão tem de abarcar o todo (he must see the whole as at one view) e compreender a cadeia e a dependência de todas as suas partes, de modo que possa introduzir cada coisa em seu lugar apropriado e possa nos conduzir suavemente ao longo da sequência de casos (affairs) que relata e nos oferecer sempre a satisfação de ver como um evento se origina de um outro (BLAIR , 2005, pp.404-405).

H á nesse trecho a defesa de um elemento que vai além da simples observação ou do mero registro factual, é necessário saber narrar e arranjar os eventos ou acontecimentos que vão compor o texto. "Ele [historiador] não demonstra qualquer arte se não for capaz de formar alguma conexão entre os casos que relata" (BLAIR, 2005, p.402), diz-nos o pensador britânico. A composição histórica deve se apresentar aos olhos de seu público como um bom quadro e formar um "todo ou inteireza". C abe ao historiador buscar "algum princípio que conecte" (BLAIR, 2005, p.397) os múltiplos casos ou eventos por ele relatados, um ponto ou elemento que mostre ao seu leitor que há unidade e acabamento em seu texto:

É por meio das circunstâncias e das particularidades adequadamente escolhidas que uma narração se torna interessante e comovente para o leitor. (...) É o emprego das circunstâncias na narração que é propriamente denominado pintura histórica (BLAIR , 2005, p.405, itálicos nossos).

Conseguir elencar um número de fatos e estabelecer os mais importantes tendo em vista o que se quer narrar são tarefas daquele que se dedica à confecção de textos de história. Como Voltaire, Blair salienta o fato de 0 historiador ter de se ater às particularidades do momento histórico que descreve e, ao mesmo tempo, saber estabelecer a conexão entre o período específico com o qual trabalha e algo maior: o que ele chama de human nature in general. Ser capaz de fazer com que o seu relato se apre- 
sente como um momento preciso de um processo tão grandioso como a história da humanidade é atributo dos bons historiadores. Embora de extrema importância, esse vínculo com uma ideia mais geral de humanidade ou de história humana não deve fazer com que a narrativa perca os detalhes e as particularidades da época que deseja retratar. C aso o faça, cairia em uma grande abstração e pecaria por ausência de precisão. A carência de imparcialidade é outro fator que pode comprometer a credibilidade de um historiador, por isso ele deve fazer o possível para fazer com que suas próprias opiniões desapareçam ao longo do que escreve. Por mais arte, habilidade e beleza que exija, seu quadro deve parecer um retrato natural e fidedigno de uma certa época ou período. Como dissemos, é necessário que se possa apreender o que há de mais preciso e particular em um momento histórico sem que se deixe de fazer desse retrato uma espécie de espelho da natureza humana, isto é: buscar na apresentação de personagens históricos uma imagem do homem em geral ou do processo no qual ele (homem) está inserido. $\mathrm{N}$ isso residiria a importante habilidade em caracterizar, que demanda que o historiador seja "simples em seu estilo" (BLAIR , 2005, p.408). U ma tal simplicidade exige cuidados: 0 exagero na criação de personagens é uma "liberdade poética que não se adéqua à seriedade da história" (BLAIR , 2005, p.408). $M$ ais uma vez Blair nos lembra que não se pode ignorar os fatos e construir uma ficção, mas também não deixa de frisar a importância que uma certa arte e invenção bem dosados têm para a composição histórica. U ma tarefa, ele admite, nada fácil:

0 desenho dos caracteres é um dos mais esplendidos e, ao mesmo tempo, um dos mais difíceis ornamentos da composição histórica (BLAIR , 2005, p.408).

A história quando bem considerada tem de pressupor experiência e gosto, atenção à beleza da composição e à observação dos fatos, ciência e arte dos que a ela se dedicam. Se os antigos careciam de precisão, os modernos são propensos a não considerar a importância da beleza ou do bom arranjo das linhas que escrevem. Em ambos os casos, o quadro permanece em aberto: não se forma um todo. G ibbon, H ume e R obertson são escritores contemporâneos a Blair que, segundo o escocês, podem exemplificar um tipo de composição histórica de língua inglesa que se 


\section{2}

preocupa em aliar matters of taste e matters of pure reasoning e, assim, buscar dar conta da questão que a própria feitura ou confecção da história coloca para os modernos. D essa preocupação que anima os historiadores do tempo de Blair,Voltaire é o grande precursor:

A pessoa com quem mais estamos em débito pela introdução desse aprimoramento em história é o célebre Sr.Voltaire, cujo gênio brilhou com surpreendente lustro em tantas e diferentes partes da literatura. Seu Século de L uís XIV é uma das primeiras grandes produções nesse gosto (BLAIR , 2005, p.412).

sucesso e a difusão de 0 Século de L uís X IV promovem e afirmam esse novo "gosto" nascente. Embora manifeste certas restrições no que diz respeito ao modo como Voltaire pensa os "temas religiosos" 15 (BLAIR, 2005, p.412), Blair reconhece no escritor francês a figura daquele que melhor representa o desafio da história moderna. Em um quadro que, para Blair, começa a ser pintado, Voltaire representa o desenho ou 0 projeto de uma história que para ser instrutiva e fidedigna também precisará agradar.

1VO LTAIR E, 1973c, p.215.

2 Sobre a história dessa publicação, as circunstâncias que deram origem ao texto das $C$ artas inglesas, bem como a repercussão e o escândalo que provocaram em sua época, ver: DELO FFR E, 1986. Préface.

${ }^{3} \mathrm{~A}$ relação entre romance e fábula, bem como outros temas a ela ligados (a crítica a D escartes, o elogio que as $\mathrm{C}$ artas Inglesas fazem do pensamento que nasce na Inglaterra do século XVII, a questão do tema da história e do experimentalismo) são analisados por R odrigo B randão em seu trabalho A ordem do mundo e 0 homem: estudos sobre metafísica e moral em Voltaire (BR AN D ÃO, 2008).

${ }^{4}$ Acerca da importância que a expressão "espírito de sistema" adquire no interior da crítica queVoltaire dirige à filosofia francesa, ver: BR AN D Ã O, 2008.

${ }^{5}$ Vale a pena lembrar que ao mesmo tempo em que a elogia nessas passagens das $C$ artas ingle sas, em outras obrasVoltaire não deixa de criticar e chamar a atenção para certos aspectos problemáticos da filosofia lockeana. Por exemplo: em 0 filósofo ignorante, ele critica as consequências que o pensador britânico extrai do argumento segundo o qual não existem ideias inatas. Para desenvolver essa sua tese, Locke recorre a relatos de viajantes que descrevem de modo fantasioso hábitos de povos selvagens, costumes exóticos que atestariam o fato de serem 
homens desprovidos de qual quer noção de moral: "Já se observou que esse grande homem foi muito crédulo relatando tais fábulas" (VO LTAIR E, 1973b, p.327). N esse sentido, Locke não poderia ser tomado como um conhecedor ou mesmo bom leitor de história na medida em que toma como dignas de confiança narrações que são visivelmente fabulosas. Há no autor britânico uma certa ingenuidade ou "simplicidade" que "não me parece desculpável", escreve Voltaire (VO LTAIR E, 1973b, p.327). Essa mesma crítica havia sido dirigida a Locke por outro autor britânico: Shaftesbury em seu Solilóquio ou conselho a um autor.

${ }^{6} \mathrm{~A}$ respeito da fábula e de sua oposição frente à noção de relato fidedigno,Voltaire afirma no início do verbete $H$ istória de seu $D$ icionário filosófico: “A H istória é a narração de fatos considerados verdadeiros, ao contrário da fábula, narração de fatos falsos" (VO LTAIRE 1973c, p.209).Ver também o verbete F ábulas do mesmo D icionário filosófico.

${ }^{7}$ Ensinar de maneira a não deixar de agradar é condição sem a qual o historiador não obtém êxito, como afirma o verbete H istória do D iconário filosófico: "Q ual é a história útil? A quela que nos mostra nossos deveres sem ter a aparência de nos querer ensiná-los" (VO LTAIR E, 1973C, p.212).

8 De acordo com a C hronologie deV oltaire que R éne Pomeau insere na edição que faz das obras históricas do autor francês, 1732 é a data em queVoltaire inicia o trabalho que terminará anos depois: 0 seu Séallo de L uís X IV (PO M EAU, 1957b, p.26). Em 1773, quando publica o seu F ragment sur I'histoire general, texto que o mesmo Pomeau insere à sua edição do $E$ ssai sur les moeurs,Voltai re ainda vincula sua reflexão acerca da história à imagem do tableau: "II y a plus de quarante ans que l'amour de la vérité, et le dégoût qu'inspirent tant d'historiens modernes, inspirèrent à une dame d'un grand nom [M me Du Châtelet] et d'un esprit supérieur à ce nom, l'envie d'étudier avec nous ce qui méritait le plus d'être observé dans le tableau general du monde, tableau si souvent défiguré" (VO LTAIR E, 1963, p.951, II). Em uma passagem do E ssai sur les moeurs em que se comenta a prática do canibalismo, tableau também é empregado para designar uma visão mais abrangente do gênero humano: " $M$ arco Paolo, ou M arc Paul, dit que, de son temps, dans une partie de laTartarie, les magiciens ou les prêtres (c'était la même chose) avai ent le droit de manger la chair des criminels condamnés à la mort.Tout cela soulève le coeur; mais le tableau du genre humain doit souvent produire cet effet" (VO LTAIR E, 1963, p.345, II). Sobre a ideia de história geral em Voltaire, a feitura e a publicação do E ssai sur les moeurs, bem como as diferenças e relações entre a referida obra e 0 Século de L uís XIV , ver: PO M EAU, 1963.

90 tema também está presente em uma carta de outubro de 1738 em queVoltaire explica ao A bbé D ubos o seu projeto de escrever o Séalo de L uís XIV : "N ão é simplesmente a vida de um príncipe que escrevo, não são os anos de seu reinado, antes é a história do espírito humano, extraída (puisée) do mais glorioso século do espírito humano" (VO LTAIR E, 1957d, p.605).

${ }^{10}$ A cerca das diferenças entre as concepções de teatro deVoltaire e de Diderot, ver o estudo que Franklin de M atos consagra ao tema no seu 0 filósofo e o comediante (FR AN KLIN DE MAT OS, 2001).

${ }^{11} \mathrm{~A}$ primeira ocorrência do termo belles-lettres é do século XVII, segundo o D icionário R obert da Língua F rancesa. Também o inglês belletristic, que aparece na expressão belletristic rhetoric (empregada para designar o tipo de atividade desempenhada por Blair), é moderno, conforme o D icionário 0 xford da L íngua Inglesa.

doispontos, Curitiba, São Carlos, vol. 8, n. 1, p.63-86, abril, 2011 


\section{4}

12 C omo o próprio Blair deixa claro, trata se de uma referência a passagens das $R$ eflex ões cíticas sobre a poesia e a pintura, do Abbé Dubos.

13 Como nos lembra R ené Pomeau, o Séalo de L uís XIV também havia sido estruturado a partir de uma divisão em quatro "séculos" ou "épocas" que correspondem aos aqui apresentados por Blair: "la Grèce, R ome, la R enaissance italienne, le siècle de Louis XIV" (PO MEAU, R . 1963, p.L).

$14 \mathrm{Em}$ seus E nsai os, $\mathrm{H}$ ume sustenta a ideia segundo a qual a obra clássica é aquela que dura ou persiste ao jugo das épocas.Ver a esse respeito 0 ensaio $D$ o padrão do gosto ( 0 f standart of taste), In: HU ME, 2010.

15 Blair não especifica o que exatamente o desagrada no modo como Voltaire trata os temas religiosos. Sendo ele ministro da igreja na Escócia, 0 autor das P releções pode ter se ressentido com o tom ou modo com que o francês trata o catolicismo e o cristianismo em geral em suas obras de cunho histórico. Acerca da noção de história em Voltaire e sua oposição frente a certas concepções históricas vinculadas à religião ou à teologia, vale destacar a comparação que Leo Spitzer propõe entre o autor do Séalo de L uís XIV e Bossuet (ver: SPIT ZER , 2005).

\section{Referências bibliográficas}

AU ER BACH , E. 1997. Figura. Tradução de D uda M achado. São Paulo: Editora Ática.

BLAIR , H . 2005. L ectures on rethoric and belles-lettres. C arbondale: Southern Illinois U niversity Press.

BR AN DÃ O, R . 2008. A ordem do mundo e o homem: estudos sobre metafísica e moral em Voltaire. São Paulo:Tese apresentada ao Departamento de Filosofia da U niversidade de São Paulo.

BU TTI DE LIM A. P. F. 1993. H istória e retórica na G réda clássica. In: Discurso 21. São Paulo: R evista do Departamento de Filosofia - USP, pp.171-186.

DELO FFR E, F. 1986. Préface. In:VO LTAIR E. Lettres philosophiques. Paris: Folio Classique.

DIDER OT, D. 2000. Paradoxo do comediante. In: D iderot- 0 bras II, E stética, poética e contos. Tradução de J.Guinsburg. São Paulo: Perspectiva. FER R EIR A-BU KLEY, L.; H ALLO R AN , S. M . 2005. Preface, 
A dknowledgements, Introductions. In: BLAIR , H . L ectures on rethoric and belles-lettres. C arbondale: Southern Illinois U niversity Press.

FR AN KLIN DE MATOS, L. F. 2001. 0 filósofo e o comediante. São Paulo/ Belo-H orizonte: H umanitas/ Editora da U FM G.

H U M E, D. 2010. A arte de escrever ensaio. Tradução de M árcio Suzuki e Pedro Paulo Pimenta. São Paulo: Iluminuras.

N ASC IM EN T O, M . G. S. 1996. Voltaire - a razão militante. São Paulo: Editora M oderna.

PO M EAU, R . 1957a. P réface. In:VO LTAIR E. 0 euvres historiques, Paris: Gallimard.

1957b. C hronologie deV oltaire. In:VO LTAIR E. 0 euvres historiques, Paris: Gallimard.

1963. Introduction. In:VO LTAIR E. E ssai sur les moeurs, Paris: Garnier,Vol. I e II.

SH AFTESBU RY 1999, Soliloquy or advice to an author. O xford: Clarendon Press, Vol.I.

SPIT ZER , L. 2005. Q uelques interprétations deV ol taire. In: SPIT ZER , L. É tudes de style. Paris: Gallimard.

VO LTAIR E 1973a. C artas inglesas. Tradução de M arilena de Souza Chauí Berlinck. Col. Pensadores. São Paulo: Editora Abril.

1973b. 0 filósofo ignorante. Tradução de M arilena de Souza C hauí Berlinck. C ol. Pensadores. São Paulo: Editora A bril.

1973c. D icionário filosófico. Tradução de Bruno da Ponte, João LopesAlves e M arilena de Souza Chauí Berlinck. Col. Pensadores. São Paulo: Editora Abril.

1957a. N ouvelles considérations sur I'histoire. In:

VO LTAIR E. 1957a. 0 euvres historiques, Paris: G allimard.

1957b. L ettre à M ilord H ervey, $G$ arde des Sceaux

d'A ngleterre. In:VO LTAIR E. 0 euvres historiques, Paris: Gallimard. 
86

1957c. L e siède de L ouis X IV . In:VO LTAIR E. O euvres historiques, Paris: G allimard.

1957d. L ettre à M . I'A bbé D u B os. In:VO LTAIR E.

0 euvres historiques, Paris: G allimard.

1986. L ettres philosophiques. Paris: Gallimard.

1963. E ssai sur les moeurs. Paris: Garnier,Vol. I e II.

1996. N ovas considerações sobre a história. In:

N ASCIM EN TO, M . G. S. 1996. Voltaire - a razão militante. São Paulo: Editora M oderna. 